\title{
Assessment of the Impact of Rosemary Chitosan Microemulsion Effect on Escherichia coli and Listeria monocytogenes Dipping in Chicken Meat Stored at $4^{\circ} \mathrm{C}$
}

\author{
Dalia Y. Youssef ${ }^{1 \dagger}$, Nahed S.A. El-Shayeb ${ }^{2 \dagger}$ and Dalia M.A. El-Masry ${ }^{3 * \dagger}$ \\ ${ }^{1}$ Department Food Hygiene, Animal Health Research Institute (AHRI), Agricultural Research Center (ARC), Egypt \\ ${ }^{2}$ Medicinal and Aromatic Plants Department, Horticulture Research Institute, ARC, Dokki, Giza, Egypt \\ ${ }^{3}$ Nanomaterials Research and Synthesis Unit, Animal Health Research Institute, ARC, Dokki, Giza, Egypt \\ *For correspondence: dr_daliaelmasry@yahoo.com \\ †Contributed equally to this work and are co-first authors \\ Received 02 September 2021; Accepted 12 December 2021; Published 30 January 2022
}

\begin{abstract}
This article studies the potential use of the Rosemarry (REO) microemulsion with/without chitosan to assess the growth inhibition of Gram-positive and Gram-negative pathogenic bacteria represented by Listeria monocytogenes and Escherichia coli. The chicken samples were divided into four groups after inoculation of E. coli and L. monocytogenes separately: control group (without treatment), $1 \%$ chitosan nanoparticle treatment group, 0.5\% REO microemulsion treatment group, and $0.5 \%$ REO $+1 \%$ chitosan microemulsion treatment group. Chicken samples were dipped into the treatments for 15 days of refrigerated storage at $4^{\circ} \mathrm{C}$. All groups were kept refrigerated, and bacterial counts were taken on days $0,1,3,6,9,12$ and 15. Chitosan nanoparticle and REO microemulsion with/without chitosan were spherical shape and showed a narrow size distribution of $23.98 \pm 0.83,34.24 \pm 2.2$ and $28.01 \pm 1.36 \mathrm{~nm}$ with a polydispersity index (PDI) of $0.86,0.33$ and 0.54 , respectively indicating that greater homogeneity was achieved. REO chitosan microemulsion has 12 components detected by GC-Mass as follows: pinene (22.21\%), borneol (21.32\%), 1-(4-methoxyphenyl) ethanoneoxime (3.48\%), oxocamphor $(0.49 \%)$, camphor (2.99\%), limonene (0.29\%), cis-linalool oxide (0.87), 2-(5-chloromethoxyphenyl) pyrrole $(2.19 \%)$, homofarnesol $(0.27 \%)$, levoverbenone $(0.45 \%)$, peruviol $(0.73 \%)$ and campesterol $(1.22 \%)$. The results showed a substantial reduction in L. monocytogenes and E. coli count in all treatment groups when compared to the control group, with the greatest inhibitory efficacy in the $0.5 \%$ REO chitosan microemulsion group. A favorable effect of chitosan treatment on chicken acceptability during refrigerated storage was reported, with an improvement in the sensory qualities of the products. Thus, REO chitosan microemulsion is advised to be used in chicken to enhance resistance to harmful microorganisms. (c) 2022 Friends Science Publishers
\end{abstract}

Keywords: Fillet; L. monocytogenes; E. coli; Chitosan; Rosemary; Microemulsion; GC-Mass

\section{Introduction}

The chicken business is growing worldwide as chicken remains one of the least expensive protein sources and white meat is considered healthier than red meat (Souza et al. 2018).

Poultry and poultry products are among the foodstuffs that must be produced and stored safely and sanitarily. Because of poor sanitary processing and storage procedures, microbial contamination occurs, leading to safety and spoiling issues. Spoiled chicken meat poses an economic hardship for farmers and necessitates new techniques to increase shelf life and overall meat safety/quality, which is the primary issue facing the poultry processing business (Petrou et al. 2012).

Food safety is one of the most critical concerns in the food business. Therefore, new procedures and technologies are being developed in the food industry to improve the quality and safety of poultry meat. In the past few years, consumer demand for nutritious food devoid of chemical preservatives has grown considerably (Petrou et al. 2012). Accordingly, there is a growing trend toward using natural ingredients derived from plants and animals, including antimicrobials, oxidants, coloring materials, and sweeteners (Mehdizadeh et al. 2020).

Listeria monocytogenes is a Gram-positive foodborne bacterium that results in serious food safety problems, particularly in meat and poultry products (Malhotra et al. 2015), because of its capacity to survive and thrive at refrigeration temperatures. Food surface treatments are crucial for food safety and quality (FAO 2013). However, as

To cite this paper: Youssef DY, NSA El-Shayeb, DMA El-Masry (2022). Assessment of the impact of rosemary chitosan microemulsion effect on E. coli and L. monocytogenes dipping in chicken meat stored at $4^{\circ} \mathrm{C}$. Intl J Agric Biol 27:69-76 
people become more aware of the possible dangers of synthetic preservatives, using a combination of natural antimicrobials and antioxidants has received great attention. Escherichia coli have been identified as a foodborne pathogen since 1982, which has greatly influenced the food sector (McClure et al. 2000).

Rosemary plant and REO are widely used as they are safe with no caveats. It is used as a flavoring agent and prevents microbial growth and rancidity development in meat through the main active compounds, such as rosmarinic acid and carnosic acid (Jongberg et al. 2013; JSMO 2016).

Rosemary oleoresin, extract, and essential oils have been identified as possible antioxidants, which are frequently utilized in the food sector (Hussain et al. 2010). The rosemary extract effectively delayed lipid oxidation in meat. Furthermore, REO has potent antibacterial action against Gram-negative and Gram-positive bacteria such as Staphylococcus aureus, Bacillus cereus, Escherichia coli and Listeria monocytogenes (Keokamnerd et al. 2008; Kahraman et al. 2015).

Chitosan is one of the natural additives originating from animals with a wide range of applications in food biopreservation due to its biodegradability, biocompatibility, nontoxicity, and antibacterial activity (No et al. 2007; Paparella et al. 2011; Grande-Tovar et al. 2018). Edible coatings and films have attracted further attention because of their ability to carry food additives, including antimicrobials, antioxidants, flavors, and colors and preserve the functionality of such agents on the food surface (Ricci et al. 2018).

Microemulsions are colloid solutions and thermodynamically stable, single optically isotropic dispersions composed of a water phase, oil phase, surfactant, and cosurfactant, with a droplet size of 10 $100 \mathrm{~nm}$ (Zhang et al. 2015). Microemulsions can be specifically used in food products because of their unique features, including ease of preparation, high-grade functions, and fine particle size; these advantages facilitate the transfer of active compounds and enhance their interactions with biomembranes (Moghimi et al. 2016). The work aimed to evaluate the effect of REO and its microemulsion with/without chitosan on inhibiting the growth of the pathogenic E. coli and L. monocytogenes inoculated in chicken fillet stored for 15 days at $4^{\circ} \mathrm{C}$.

\section{Materials and Methods}

\section{Preparation and extraction of REO}

The fresh herb of Rosmarinus officinalis was brought from the experimental farm at the Medicinal and Aromatic Plants Research Department in Gezert El-Shaeer, El Qanatir El Khayriyah, Egypt. The essential oil was extracted using the water-steam distillation method (Cliventer system) on the whole fresh herb samples for $3 \mathrm{~h}$ in the Medicinal and
Aromatic Plants Lab, Dokki, Giza, according to Miller method (1963).

\section{Preparation and Treatments of Chitosan Nanoparticles}

The $1 \%$ chitosan nanoparticle was spontaneously obtained upon adding 1 and $0.5 \%$ acetic acid chitosan acidic solutions, respectively, to $0.7 \mathrm{mg} / \mathrm{mL}$ solutions of TPP aqueous basic solution. The ratio of TTP to chitosan was 1:3 under magnetic stirring at room temperature for $1 \mathrm{~h}$ according to Youssef and El-Masry (2018).

\section{Preparation of Rosemary Microemulsion with or without Chitosan}

Rosemary oil (0.5\%) was mixed with tween $80(4.5 \%)$ as an emulsifier and was stirred for $30 \mathrm{~min}$. The $1 \%$ chitosan solution was added to form and obtain a uniform, stable and clear emulsion, according to Rao and McClements (2011). A $1 \%$ sodium chloride solution is used to replace chitosan in the other treatment.

\section{Characterization of Chitosan Nanoparticle and Microemulsion}

Zetasizer Malvern Instrument (Corp, Malvern, UK) was used to measure surface charge (zeta potential), droplet size, size distribution (polydispersity indexes) and electrical conductivity of the microemulsion. High-resolution transmission electron microscopy (HRTEM) observations were performed using a JEM 1400F HRTEM at beam energy of $300 \mathrm{keV}$.

The examined samples determined using direct capillary column $(30 \mathrm{~m} \times 0.25 \mathrm{~mm} \quad \times 0.25 \mu \mathrm{m}$ film thickness) of Trace GC-TSQ mass spectrometer (Thermo Scientific, Austin, TX, USA) for chemical composition. The components were identified by comparing their mass spectra with those of WILEY 09 and NIST 14 mass spectral database according to El-Kareem et al. (2016).

\section{Cell Culture}

Green monkey cell line (Vero cell) purchasing from Nawah Scientific, Inc. (Cairo, Egypt), was maintained in media supplemented with $10 \%$ of fetal bovine heat-inactivated serum, streptomycin $(100 \mathrm{mg} / \mathrm{mL})$ and penicillin $(100$ units $/ \mathrm{mL}$ ) at $37^{\circ} \mathrm{C}, 5 \%$ humidity and $\mathrm{CO}_{2}$ atmosphere. Cytotoxicity and cell viability assays were performed using the SRB assay at different solution concentrations $(0.01,0.1$, 1,10 and $100 \mu \mathrm{g} / \mathrm{mL}$ ), according to Allam et al. (2018).

\section{Preparation of Microbial Inoculums}

Strains from the Animal Health Research Institute of E. coli (ATCC 8739) and L. monocytogens (ATCC 14028) were acquired (Food Hygiene Department). Frozen crops were 
kept at $-80^{\circ} \mathrm{C}$ and activated in $9 \mathrm{~mL}$ of trypticase soy broth (TSB) during incubation at $35^{\circ} \mathrm{C}$ for $24 \mathrm{~h}$ with two successive passes. For individual strains, $1 \mathrm{~mL}$ of the inoculum was introduced to $100 \mathrm{~mL}$ (TSB) of stock and the Oxoid Incubator Shaker was used to obtain an estimated concentration of about $10^{8} \mathrm{CFU} / \mathrm{mL}$ as measured by a 0.5 McFarland standard using plating serial dilutions on ALOA and TBX agar. Two serial dilutions of $1 \mathrm{~mL}$ of this inoculum have been added to a $9 \mathrm{~mL}$ sterile saline to obtain the final concentration of around $10^{6} \mathrm{CFU} / \mathrm{g}$.

\section{Dipping of chicken samples}

Fresh chicken fillets (10 kg) from a market shop in Cairo, Egypt, without skin were purchased and immediately brought to the refrigerated lab. Then, they were divided into four groups of duplicates and placed under running tap water for two minutes to remove foreign bodies or remains or foreign bodies.

The chicken fillets were contaminated with inoculated soaking solution for one minute and then with the $L$. monocytogenes and E. coli strains for $20 \mathrm{~min}$ and were dried in a laminar airflow (four groups for each strain) (Olaimat and Holley 2015).

\section{Preparation of treatments}

The previously dipped samples were treated using three different immersing solutions: (1) $1 \%$ chitosan nanoparticles; (2) $0.5 \%$ REO microemulsion; (3) $0.5 \%$ REO $+1 \%$ chitosan microemulsion for $1 \mathrm{~min}$. Then, the samples for drained for $15 \mathrm{~min}$ and stored at $4{ }^{\circ} \mathrm{C}$ for 16 days. Finally, the analysis was performed on days $0,1,3,6,9,12$ and 15 of refrigerated storage (Sharifi et al. 2017). Two groups were assigned as positive controls for $L$. monocytogenes and E. coli $\left(10^{6} \mathrm{CFU} / \mathrm{mL}\right)$.

\section{Enumeration of $E$. coli}

With $0.1 \%$ sterile peptone water, chicken fillet samples $(10 \mathrm{~g})$ were brought to a final volume of $90 \mathrm{~mL}$. A stomacher was used to homogenize the materials for $2 \mathrm{~min}$. (Seward Medical, London). Following the production of decimal dilutions, $1 \mathrm{~mL}$ of successive homogenate dilutions was cultivated onto TBX agar and incubated at $35^{\circ} \mathrm{C}$ for $24 \mathrm{~h}$.

\section{Enumeration of L. monocytogenes}

25 grams of immunized fillets was stomached in $225 \mathrm{~mL}$ of Listeria broth and serially diluted using maximal recovery to be counted on selective medium (ALOA agar). Moreover, 1 $\mathrm{mL}$ of serial dilutions of homogenates was cultivated onto duplicate plates and incubated at $35^{\circ} \mathrm{C}$ for $24 \mathrm{~h}$.

All fillets were sealed in plastic bags and stored on a refrigerator shelf for future examination. Each inoculation group was regularly inspected for the inoculated strain count as detect in the primary count at days $0,1,3,6,9,12$ and 15 of refrigerated storage to assess the influence of the treatments on the viability of the injected bacterial strains.

\section{Sensory evaluation}

For studying the effect of rosemary with/without chitosan microemulsion on the sensory attributes of chicken fillets, four groups of chicken fillet were prepared by dipping in solutions as follows: one group of chicken fillet with $1 \%$ chitosan nanoparticles, $0.5 \% \quad \mathrm{REO}+1 \% \quad$ chitosan microemulsion and $0.5 \%$ REO microemulsion, the last group without treatment.

After $15 \mathrm{~min}$ of group treated and then it was permitted to dry for another $15 \mathrm{~min}$ in the laminar flow before being kept in the refrigerator at $4^{\circ} \mathrm{C}$.

All samples of cooked chicken fillets were organoleptically evaluated by seven panelists from the staff members, according to Petrou et al. (2012). Only edible chicken fillets from the control and treatment groups were cooked for $5 \mathrm{~min}$ in a microwave oven set to high power $(700 \mathrm{~W})$. Using a nine-point hedonic scale, seven panelists were asked to rate the acceptability (total sensory assessment score) in terms of odor, taste, and sight: 9 , excellent; 8 , very good; 7, good; 6, bad (initial off-odor, off-taste development). A score of 6 was chosen as the bottom limit of acceptability. After the emergence of the first off-odor or undesirable color, the sample was deemed unsuitable.

\section{Statistical analysis}

Each test was done thrice, and standard deviation mean value (SD) was given for each occurrence. All data were analyzed using ANOVA on a single-way basis and mean separation was performed using Tukey's multiscope test (SPSS 19.0). Differences at $P 0.05$ level were considered significant.

\section{Results}

Characterization of chitosan nanoparticle and REO microemulsion (with or without coating chitosan)

Particle Size, Morphology, and Size Distribution. TEM was used to determine the size and morphology of the nanoparticles. Three nanomaterials were spherical and showed no aggregation and narrow size distribution of $23.98 \pm 0.83,34.24 \pm 2.2$ and $28.01 \pm 1.36 \mathrm{~nm}$ (Fig. 1a-c) with a polydispersity index (PDI) of $0.86,0.33$ and 0.54 , respectively, indicating that greater homogeneity can be realized.

The zeta potential, which indicates unstable and stable suspensions, is often measured via dynamic light scattering (DLS). The zeta potential results for chitosan nanoparticle, rosemary chitosan microemulsion, and rosemary microemulsion were $53.5 \pm 5.14 \mathrm{mV}, \quad 9.69 \pm 3.67 \mathrm{mV}$, $43.3 \pm 6.23 \mathrm{mV}$, respectively, measured at $\mathrm{pH} 5$. 

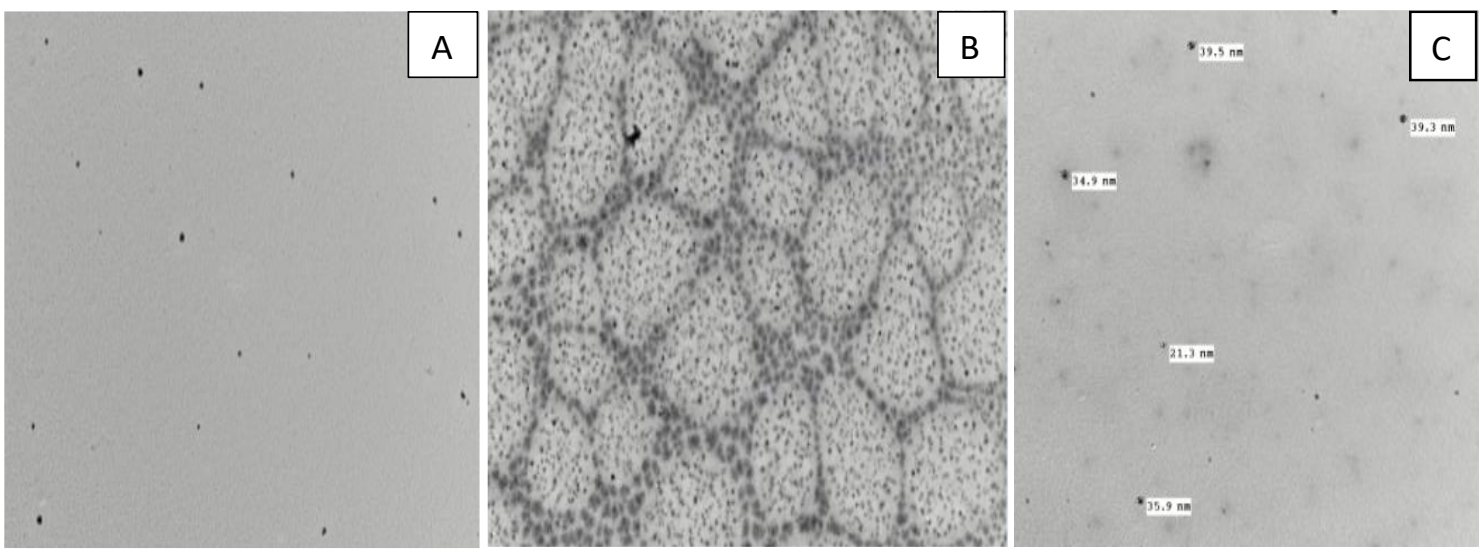

Fig. 1: TEM of (A) chitosan nanoparticle and (B): rosemary chitosan microemulsion and $(\mathbf{C})$ rosemary microemulsion
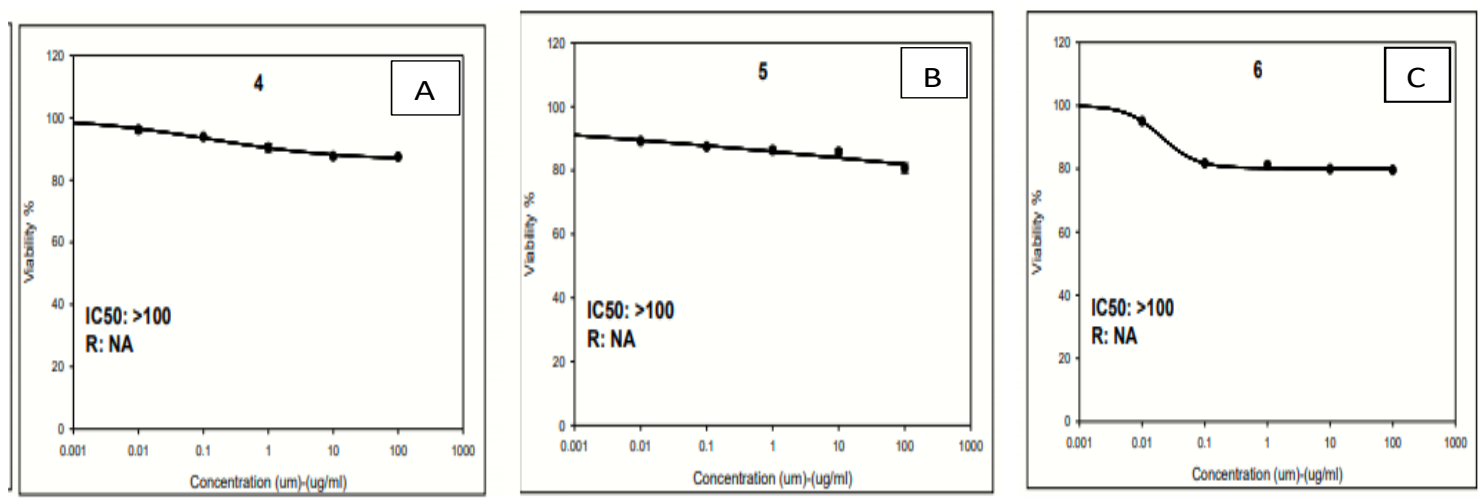

Fig. 2: Cell viability \% of $(\mathbf{A})$ chitosan nanoparticle and $(\mathbf{B})$ : rosemary chitosan microemulsion and $(\mathbf{C})$ rosemary microemulsion

The analysis of the rosemary oil using GC-Mass showed the presence of terpineol (6.29\%), camphor $(37.82 \%)$, isoborneol $(25.96 \%)$, levoverbenone $(17.92 \%)$, citronellol $(0.90 \%)$, isopulegol $(1.53 \%)$, bornyl acetate $(2.68 \%)$, sobrerol 8 -acetate $(1.09 \%)$, and caryophyllene oxide $(2.46 \%)$. On the other hand, rosemary chitosan microemulsion had 12 componentsL 1-(4-methoxyphenyl) ethanoneoxime (3.48\%), oxocamphor $(0.49 \%)$, $\alpha$-pinene $(22.21 \%)$, camphor $(2.99 \%)$, limonene $(0.29 \%)$, borneol $(21.32 \%)$, cis-linalool oxide $(0.87), \quad 2$-(5-chloromethoxyphenyl) pyrrole (2.19\%), homofarnesol $(0.27 \%)$, levoverbenone $(0.45 \%)$, peruviol $(0.73 \%)$ and campesterol $(1.22 \%)$.

On the confluent surface of Vero cells, chitosan nanoparticles and rosemary with or without chitosan microemulsion had different concentrations $(0.01,0.1,1,10$, and $100 \mathrm{ug} / \mathrm{mL}$ ) after 3 days of inoculation. The cell viability\% assessed by SRB assay was $87.43 \%, 80.69 \%$, and $79.66 \%$, respectively, in $100 \mu \mathrm{g} / \mathrm{mL}$ and $\mathrm{IC}_{50}>100$ $\mu \mathrm{g} / \mathrm{mL}$ (Fig. 2a-c).

Inhibitory effect of different treatments on $L$. monocytogenes and $E$. coli

Table 1 and Fig. 3 show the effectiveness of different treatments on the behavior of L. monocytogenes during refrigerated storage of chicken fillets samples. By comparing the treated samples with the samples inoculated with the strains in the absence of treatment (positive control) at zero days, the initial count of $L$ monocytogenes was 5.65 $\pm 0.55 \log$ CFU/g. At 1 day after treatment, the counts of the pathogens in treated samples with $0.5 \%$ REO microemulsion, $1 \%$ chitosan nanoparticle, and $0.5 \%$ $\mathrm{REO}+1 \%$ chitosan microemulsion were reduced compared to control, whereas, in the control sample, the count remained $5.77 \pm 0.16 \log \mathrm{CFU} / \mathrm{g}$.

The count of treated chicken fillet was reduced to $5.62 \pm 0.34, \quad 4.71 \pm 0.27$ and $4.18 \pm 0.74 \log \mathrm{CFU} / \mathrm{g}$, respectively. Significant differences $(P<0.05)$ were observed between means having different letters in the same row between the three groups. Dipping chicken fillets into $0.5 \%$ REO microemulsion, $1 \%$ chitosan nanoparticle, and $0.5 \%$ REO $+1 \%$ chitosan microemulsion reduced the $L$. monocytogenes count to about $1.7,2$ and $3 \log \mathrm{CFU} / \mathrm{g}$, respectively, during refrigerated storage up to 15 days. Chitosan coatings are commonly mixed with essential oils and created in the form of microemulsions during refrigerated storage at $4^{\circ} \mathrm{C}$ to intensify the impact of chitosan against foodborne bacteria.

Table 2 and Fig. 4 show the effect of different 
Rosemarry Microemulsion as Antibacterial on Chicken Fillet / Intl J Agric Biol, Vol 27, No 1, 2022

Table 1: Listeria monocytogenes count (Log CFU/g) of inoculated chicken fillet stored at $4{ }^{\circ} \mathrm{C}(\mathrm{Mean} \pm \mathrm{SD})$

\begin{tabular}{lllll}
\hline Storage days & Control & $0.5 \%$ REO micro emulsion & $1 \%$ Chitosan nanoparticle & $0.5 \%$ REO $+1 \%$ Chitosan micro emulsion \\
\hline Zero day & $6.17^{\mathrm{a}} \pm 0.72$ & $5.58^{\mathrm{a}} \pm 0.25$ & $5.51^{\mathrm{a}} \pm 0.44$ & $5.83^{\mathrm{a}} \pm 0.29$ \\
$1^{\text {st }}$ day & $5.77^{\mathrm{a}} \pm 0.16$ & $5.62^{\mathrm{a}} \pm 0.34$ & $4.71^{\mathrm{b}} \pm 0.27$ & $4.18^{\mathrm{b}} \pm 0.74$ \\
$3^{\text {rd }}$ day & $5.68^{\mathrm{a}} \pm 0.11$ & $4.52^{\mathrm{b}} \pm 0.12$ & $4.20^{\mathrm{bc}} \pm 0.69$ & $3.84^{\mathrm{c}} \pm 0.11$ \\
$6^{\text {th }}$ day & $6.08^{\mathrm{a}} \pm 0.81$ & $4.48^{\mathrm{b}} \pm 0.52$ & $3.46^{\mathrm{c}} \pm 0.33$ & $3.55^{\mathrm{bc} \pm 0.42}$ \\
$9^{\text {th }}$ day & $6.76^{\mathrm{a}} \pm 0.21$ & $3.84^{\mathrm{b}} \pm 0.09$ & $3.65^{\mathrm{b}} \pm 0.60$ & $3.30^{\mathrm{b}} \pm 0.61$ \\
$12^{\text {th }}$ day & $6.81^{\mathrm{a}} \pm 0.06$ & $3.54^{\mathrm{b}} \pm 0.21$ & $3.04^{\mathrm{b}} \pm 0.92$ & $3.27^{\mathrm{b}} \pm 0.63$ \\
$15^{\text {th }}$ day & $7.48^{\mathrm{a}} \pm 0.52$ & $3.89^{\mathrm{b}} \pm 0.10$ & $3.62^{\mathrm{b}} \pm 0.58$ & $2.89^{\mathrm{c}} \pm 0.08$ \\
\hline
\end{tabular}

There are significance differences $(P<0.05)$ between means having different letters in the same raw

Table 2: E. coli count (Log CFU/g) of inoculated chicken inoculated chicken fillet stored at $4^{\circ} \mathrm{C}(\mathrm{Mean} \pm \mathrm{SD})$

\begin{tabular}{lllll}
\hline Storage days & Control & $0.5 \%$ REO micro emulsion & $1 \%$ Chitosan nanoparticle & $0.5 \%$ REO $+1 \%$ Chitosan micro emulsion \\
\hline Zero day & $6.19^{\mathrm{a}} \pm 0.55$ & $6.02^{\mathrm{a}} \pm 0.75$ & $5.70^{\mathrm{a}} \pm 0.02$ & $4.43^{\mathrm{b}} \pm 0.70$ \\
$1^{\text {st }}$ day & $6.26^{\mathrm{a}} \pm 0.64$ & $5.64^{\mathrm{ab}} \pm 0.42$ & $4.90^{\mathrm{bc}} \pm 0.14$ & $4.54^{\mathrm{c}} \pm 0.53$ \\
$3^{\text {rd }}$ day & $6.46^{\mathrm{a}} \pm 0.45$ & $4.16^{\mathrm{b}} \pm 0.54$ & $4.06^{\mathrm{b}} \pm 0.37$ & $3.69^{\mathrm{b}} \pm 0.36$ \\
$6^{\text {th }}$ day & $5.49^{\mathrm{a}} \pm 0.18$ & $4.25^{\mathrm{b}} \pm 0.71$ & $4.12^{\mathrm{b}} \pm 0.77$ & $3.53^{\mathrm{b}} \pm 0.24$ \\
$9^{\text {th }}$ day & $5.85^{\mathrm{a}} \pm 0.17$ & $3.72^{\mathrm{b}} \pm 0.24$ & $3.67^{\mathrm{b}} \pm 0.27$ & $2.88^{\mathrm{c}} \pm 0.36$ \\
$12^{\text {th }}$ day & $6.64^{\mathrm{a}} \pm 0.33$ & $3.85^{\mathrm{b}} \pm 0.26$ & $3.00^{\mathrm{c}} \pm 0.16$ & - \\
$15^{\text {th }}$ day & $7.30^{\mathrm{a}} \pm 0.60$ & $3.66^{\mathrm{b}} \pm 0.35$ & - & - \\
\hline \multicolumn{7}{l}{ There are significance differences $(P<0.05)$ between means having different letters in the same raw }
\end{tabular}

Table 3: Overall Sensory Scores (Mean \pm SD) of chicken fillet stored at $4^{\circ} \mathrm{C}$

\begin{tabular}{lllll}
\hline Storage period & Control & $0.5 \%$ REO microemulsion & $1 \%$ chitosan nanoparticle & $0.5 \%$ REO+ $1 \%$ chitosan microemulsion \\
\hline Zero day & $9.0 \pm 0.0$ & $9.00 \pm 0.0$ & $9.00 \pm 0.0$ & $9.00 \pm 0.0$ \\
$1^{\text {st }}$ day & $8.8^{\mathrm{a}} \pm 0.45$ & $8.8^{\mathrm{a}} \pm 0.45$ & $8.8^{\mathrm{a}} \pm 0.45$ & $8.8^{\mathrm{a}} \pm 0.45$ \\
$3^{\text {rd }}$ day & $8.50^{\mathrm{a}} \pm 0.45$ & $8.50^{\mathrm{a}} \pm 0.45$ & $8.50^{\mathrm{a}} \pm 0.45$ & $8.50^{\mathrm{a}} \pm 0.45$ \\
$6^{\text {th }}$ day & $6.20^{\mathrm{a}} \pm 0.45$ & $8.20^{\mathrm{b}} \pm 0.45$ & $8.20^{\mathrm{b}} \pm 0.45$ & $8.20^{\mathrm{b}} \pm 0.45$ \\
$9^{\text {th }}$ day & $4.45^{\mathrm{a}} \pm 0.45$ & $8.20^{\mathrm{b}} \pm 0.45$ & $8.20^{\mathrm{b}} \pm 0.45$ & $8.20^{\mathrm{b}} \pm 0.45$ \\
$12^{\text {th }}$ day & $2.45^{\mathrm{a}} \pm 0.45$ & $6.67^{\mathrm{a}} \pm 0.45$ & $6.20^{\mathrm{b}} \pm 0.45$ & $6.20^{\mathrm{b}} \pm 0.45$ \\
\hline
\end{tabular}

There are significance differences $(P<0.05)$ between means having different letters in the same raw

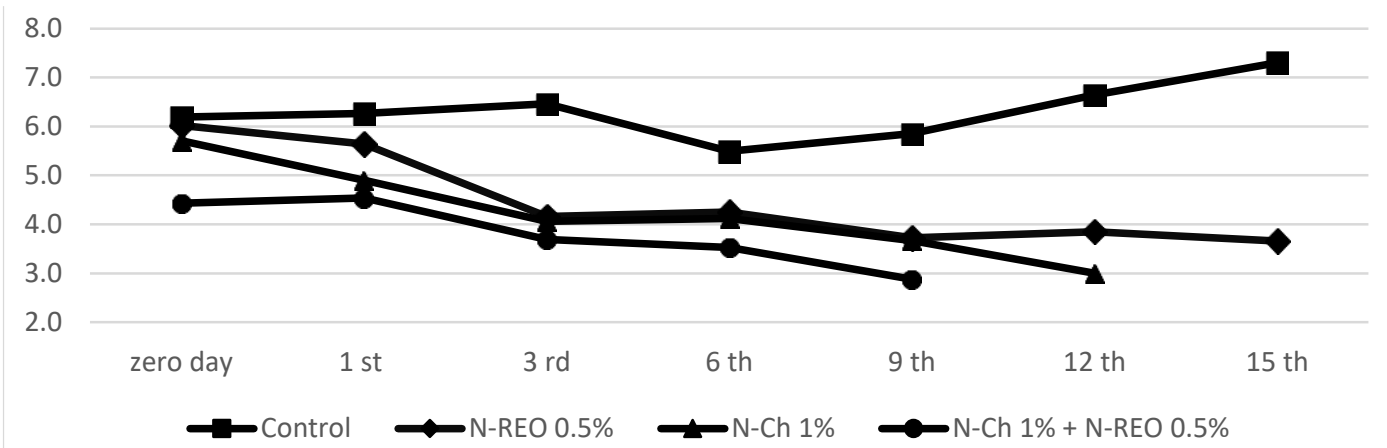

Fig. 3: Mean count of L. monocytogenes in different treatments during storage

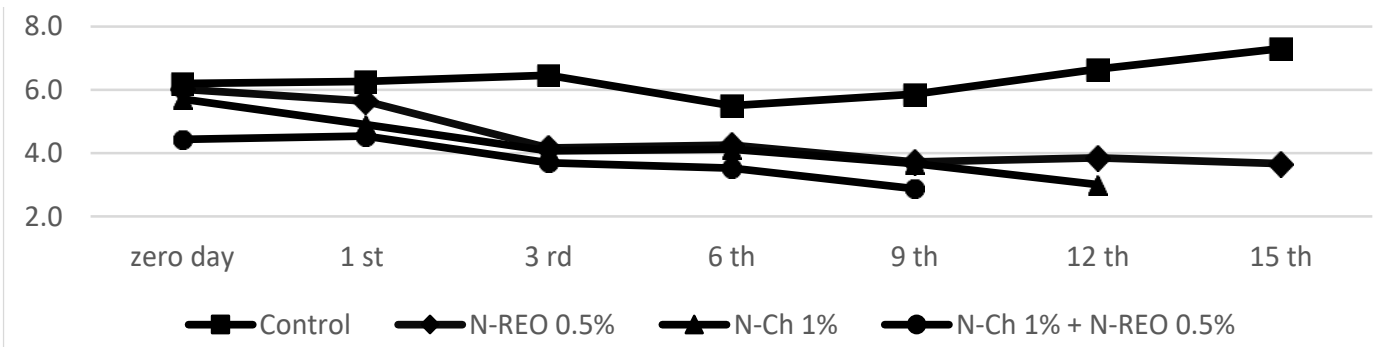

Fig. 4: Mean count of E. coli in different treatments during storage

treatments on the growth of $E$. coli during 15 days of refrigerated storage. The initial count of E. coli was 6.00 $\pm 0.05 \mathrm{Log} \mathrm{CFU} / \mathrm{g}$ in control samples and other treatments. The growth of $E$. coli decreased at $4^{\circ} \mathrm{C}$ in all treatments. The maximum bacterial count was observed in control samples on the $15^{\text {th }}$ day of storage $(7.45 \pm 0.13 \mathrm{Log} \mathrm{CFU} / \mathrm{g})$, whereas the minimum count was observed in $0.5 \% \mathrm{REO}+1 \%$ chitosan microemulsion samples (on $8^{\text {th }}$ day of storage: 3.15 
$\pm 0.21 \log \mathrm{CFU} / \mathrm{g} ; 12^{\text {th }}$ and $15^{\text {th }}$ the counts were less than 3 $\log \mathrm{CFU} / \mathrm{g}$ ). When compared to the control group, the results demonstrated a significant drop in E. coli count in all treatments with REO chitosan microemulsion having the strongest inhibitory efficacy.

\section{Sensory evaluation}

The sensory analysis results are reported in Table 3 . The overall acceptability in terms of appearance, color, odor and texture of all samples started at a score of 9. Within 2 days of storage, no significant changes in the samples were found $(P$ 0.05). Three days later, significant changes were observed, as with the scores of the control samples were considerably recorded lower than those of any other treated samples $(P 0.05)$. Based on these sensory scores, especially overall acceptability, the $0.5 \%$ REO $+1 \%$ chitosan microemulsion mixture yielded the highest acceptability scores between 6 and 9 days of storage.

\section{Discussion}

Previous studies have reported that the mean rosemary nanoemulsion particle size ranges from $164 \pm 9$ to $676 \pm 26 \mathrm{~nm}$ and the mean PDI was $0.230 \pm 0.009$ (Restrepo et al. 2018). REO is used to make a variety of products. Ultrasound was used for 6 min to create a nanoemulsion with a droplet size of $139.9 \mathrm{~nm}$. The lethal concentration $\left(\mathrm{LC}_{50}\right)$ of spray application of normal emulsion (EO) was $1,578.50$ and $1,829.94 \mathrm{~g} / \mathrm{mL}$ for juvenile and adult female spider mites, respectively (Mossa et al. 2019).

Nanocapsules containing rosemary oil were of average size $(145 \pm 15 \mathrm{~nm})$ with PDI below 0.3 and negative zeta potential $(-11,0 \pm 0.5 \mathrm{mV})$; they were spherical nanocapsules with regular and homogeneous surfaces. The following key components have been identified in REO using GC-MS: $\alpha$-pinene (16.07\%), 1.8-cineol (13.99\%), camphor $(10.85 \%)$ and cis-verbenone $(10.16 \%)$ (Khoobdel et al. 2017).

$\alpha$-Pinene is a major constituent in the composition oil, which has antibacterial activity against Gram-negative and Gram-positive bacteria. In the case of REO, major and minor active components, such as borneol, 1,8 cineole, Dlimonene, $\alpha$-pinene, L-linalool, $\gamma$-terpinene, D-camphor, pcymene, $\alpha$-terpineol, sabinene, $\alpha$-myrcene, a-thujenol, isocineole, $\alpha$-phellandrene, $\alpha$-terpinene, myrtenol, $\alpha$ terpinolene, 4-terpineol, terpinene-1-ol, $\gamma$-terpineol, isopulegol acetate and geraniol have acaricidal activity against several phytophagous mites (Mossa et al. 2019). GC/MS analysis of REO showed that $\gamma$-terpinene (3.92\%), borneol (11.07\%), 1,8 cineole (31.45\%), D-limonene (9.19\%), $\alpha$-pinene $(10.91 \%), \quad$ L-linalool $(8.86 \%), \quad$ Dcamphor $(7.32 \%)$, $\alpha$-terpineol $(3.32 \%)$, linalyl acetate (3.37\%), and p-cymene (1.82\%) were the major components (Gachkar et al. 2007; Ebadollahi et al. 2014).

Therefore, the powerful synergistic antimicrobial activity of the rosemary chitosan microemulsion against Gram-positive bacteria L. monocytogenes resulted in a lower microbial count and inhibition of the microbiological growth of L. monocytogenes by $3 \log \mathrm{CFU} / \mathrm{g}$. These results agreed with those by Ismail et al. (2015), who reported that the number of bacteria decreased in samples wrapped in bionano composites (1.2-2.6 log CFU/g). Moreover, Souza et al. (2019) have stated similar results in fresh chicken breast fillets coated with sodium caseinate incorporated with a nanoemulsion of ginger essential oil. Moreover, Noori et al. (2018) has shown the reduction of the population of the inoculated meatballs covered with chitosan. The counts of L. monocytogenes were around $2 \log \mathrm{CFU} / \mathrm{g}$ lower, showing the inhibitory effect of L. monocytogenes on chitosan growth. On the other hand, Antoniadou et al. (2019) have studied edible chitosan film and claimed that the growth of $L$. monocytogenes could not be avoided in RTE beef dissolved at $0.5 \%(\mathrm{w} / \mathrm{v}), 0.5 \%(\mathrm{w} / \mathrm{v})$, or $1 \%(\mathrm{w} / \mathrm{v})$ and stored at $4^{\circ} \mathrm{C}$. However, on day 14 , the number of $L$. monocytogenes for all chitosan encapsulated samples was significantly distinct from that of control by $2-3 \log \mathrm{CFU} / \mathrm{g}$; On day 15 , it was significantly different. This could be attributed to chitosan films having less antibacterial activity as an amino group is less available on chitosan (Coma et al. 2002; Cagri et al. 2004; Beverlya et al. 2008).

Several previous studies (Raeisi et al. 2012; Shahbazi et al. 2015; Ehsani et al. 2016) have confirmed the above finding. Nevertheless, chitosan films may have antagonistic, synergistic, or additive effects based on the type of antimicrobial agent and microorganism. The present study confirmed that the application of coating treatments could eliminate the bacterial count to an undetectable $\left(10^{3} \mathrm{CFU} / \mathrm{g}\right)$ level. As mentioned, this could be due to the use of coating solutions containing REO as microemulsions.

The effects of $1 \%$ chitosan are similar to those found in previous research (Youssef and El-Masry 2018), which indicated the significant antimicrobial activity of $0.5,1$ and $2 \%$ chitosan nanoparticles in eradicating foodborne pathogens and maintaining an acceptable sensory quality of chicken meat.

The primary components found in prepared REO microemulsions, such as $\alpha$-pinene, 1,8-cineol, camphor, myrcene, camphene, borneol and verbenone, significantly contributed to the high antioxidant and antibacterial activities of REO against L. monocytogenes, E. coli, Salmonella indiana, and Listeria innocua (Abdullah et al. 2015).

Previous research (Hassanzadazar et al. 2019) had found that in comparison to Gram-negative bacteria, REO and REO nanoemulsion have more important antibacterial properties and effects on Shewanella spp., $L$. monocytogenes x Staphylococcus aureus, S. enteritidis, E. coli, and $P$. aeruginosa. The REO nanoemulsion mechanism of action in Gram-positive bacteria is explained by the fact that (Aminzare et al. 2017) the cell membrane was improved by the ion's permeability due to direct 
interaction between the phospholipid layer of the cell membrane and the lipophilic components of EO and the lack of an external phospholipid membrane-aided intraexcretion.

Our findings did not agree with those by Ntzimani $e t$ al. (2010), who found that applying REO (0.2\%) to cooked chicken produced an acceptable odor and taste. The obtained results revealed higher sensorial scores in $0.5 \% \mathrm{REO}+1 \%$ chitosan microemulsion samples, which indicate the effects of chitosan coating on preserving sensory characteristics of chicken meat. The results were in line with those of Hassanzadeh et al. (2017). Color influences the customer's preferences and choice of food. Food color is determined by the chemical, biochemical, physical, and microbial changes occurring during storage. Accordingly, chitosan's antioxidant qualities and its capacity to function as a metal ion transition chelator that catalyzes myoglobin oxidation can cause redness in muscle food (Yen et al. 2008).

\section{Conclusion}

This study has demonstrated the counts of $E$. coli and $L$. monocytogenes, which were considerably lowered after treatment for cold chicken fillets with the REO chitosan microemulsion. Compared to the control samples, the sensory characteristics were improved and the storage quality of the chicken breast muscle was retained in the cooling phase. Naturally retaining the storage quality of the chicken breast muscle in conjunction with the microemulsion of chitosan could be a viable technique in the food industry.

\section{Acknowledgements}

The authors are grateful to Dr. Kalid Tolba and Dr. Khaled El Khawas, AHRI's members for their scientific review and recommendations.

\section{Author Contributions}

All authors designed, coordinated, and conducted the experiment, analyzed the data, and wrote the manuscript. All authors read and approved the final manuscript.

\section{Conflicts of Interest}

All authors declare no conflicts of interest.

\section{Data Availability}

Data presented in this study will be available on a fair request to the corresponding author.

\section{Ethics Approval}

Not applicable in this paper.

\section{References}

Abdullah BH, SF Hatem, WA Jumaa (2015). Comparative study of the antibacterial activity of clove and rosemary essential oils on multidrug resistant bacteria. Pharm Biosci J 3:18-22

Allam RM, AM Al-Abd, A Khedr, OA Sharaf (2018). Fingolimod interrupts the cross talk between estrogen metabolism and sphingolipid metabolism within prostate cancer cells. Toxicol Lett 291:77-85

Aminzare M, M Hashemi, H Hassanzadazar, E Amiri, Z Abbasi (2017). Antibacterial activity of corn starch films persicum essential Oils. Annu Res Rev Biol 19:1-9

Antoniadou D, A Govaris, I Ambrosiadis, D Sergelidis (2019). Effect of chitosan coating on the shelf life of ready-to-eat bovine meatballs and the control of Listeria monocytogenes growth on their surface during refrigeration storage. J Hell Vet Med Soc 70:1495-1502

Beverlya RL, ME Janes, W Prinyawiwatkula, HK No (2008). Edible chitosan films on ready-to-eat roast beef for the control of listeria monocytogenes. Food Microbiol 25:534-537

Cagri A, Z Ustunol, ET Ryser (2004). Antimicrobial edible films and coatings. J Food Prot 67:833-848

Coma V, A Martial-Gros, S Garreau, A Copinet, F Salin, A Deschamps (2002). Edible antimicrobial films based on chitosan matrix. J Food Sci 67:1162-1169

Ebadollahi A, JJ Sendi, A Aliakbar, J Razmjou (2014). Chemical composition and acaricidal effects of essential oils of Foeniculum vulgare Mill. (Apiales: Apiaceae) and Lavandula angustifolia Miller (Lamiales: Lamiaceae) against Tetranychus urticae Koch (Acari: Tetranychidae). Psyche 2014:1-6

Ehsani A, M Hashemi, SS Naghibi, S Mohammadi, SK Sadaghiani (2016). Properties of Bunium persicum essential oil and its application in Iranian white cheese against Listeria monocytogenes and Escherichia coli O157: H7. J Food Saf 36:563-570

El-Kareem MMA, MAEF Rabbih, ETM Selim, EAEM Elsherbiny, AY ElKhateeb (2016). Application of GC/EIMS in combination with semiempirical calculations for identification and investigation of some volatile components in basil essential oil. Intl J Anal Mass Spectr Chromatogr 4:14-25

FAO (2013). Poultry Development Review; FAO: Rome, Italy, ISBN 97892-5-108067-2

Gachkar L, D Yadegari, MB Rezaei, M Taghizadeh, SA Astaneh, I Rasooli (2007). Chemical and biological characteristics of Cuminum cyminum and Rosmarinus officinalis essential oils. Food Chem 102:898-904

Grande-Tovar C, C Chaves-López, A Serio, C Rossi, A Paparella (2018). Chitosan coatings enriched with essential oils: Effects on fungi involve in fruit decay and mechanism of action. Trends Food Sci Technol 78:61-71

Hassanzadazar H, SYA Ghafari, M Fathollahi, M Aminzare (2019). Antimicrobial effects of the nanoemulsion of rosemary essential oil against important foodborne pathogens. J Hum Environ Health Prom 5:79-85

Hassanzadeh P, H Tajik, SMR Rohani, M Moradi, M Hashemi, J Aliakbarlu (2017). Effect of functional chitosan coating and gamma irradiation on the shelf-life of chicken meat during refrigerated storage. Radiat Phys Chem 141:103-109

Hussain AI, F Anwar, SAS Chatha, A Jabbar, S Mahboob, PS Nigam (2010). Rosmarinus officinalis essential oil: Antiproliferative, antioxidant and antibacterial activities. Braz $J$ Microbiol 41:1070-1078

Ismail MS, MF Soliman, AH Abo-Ghalia, MM Ghallab (2015). The acaricidal activity of some essential and fixed oils against the twospotted spider mite in relation to different temperatures. Intl J Pest Manage 61:121-125

JSMO - Jordan Standards and Metrology Organization (2016). List and publications: List of allowed additives in food products. Codex Standard n 192 and European Directives. JSMO, Jordan

Jongberg S, MA Torngren, A Gunvig, LH Skibsted, MN Lund (2013). Effect of green tea or rosemary extract on protein oxidation in Bologna type sausages prepared from oxidatively stressed pork. Meat Sci 93:538-546 
Kahraman T, G Issa, EB Bingol, BB Kahraman, E Dumen (2015). Effect of rosemary essential oil and modified-atmosphere packaging (MAP) on meat quality and survival of pathogens in poultry fillets. Braz $J$ Microbiol 46:591-599

Keokamnerd T, JC Acton, IY Han, PL Dawson (2008). Effect of commercial rosemary oleoresin preparations on ground chicken thigh meat quality packaged in a high-oxygen atmosphere. Poult Sci 87:170-179

Khoobdel M, SM Ahsaei, M Farzaneh (2017). Insecticidal activity of polycaprolactone nanocapsules loaded with Rosmarinus officinalis essential oil in Tribolium castaneum (Herbst). Entomol Res 47:175-184

Malhotra P, L Vig, G Shroff, P Agarwal (2015). Long short-term memory networks for anomaly detection in time series. In: Proceedings European Symposium on Artificial Neural Networks, Computational Intelligence and Machine Learning. 22-24 April, 2015. Bruges Belgium

McClure $\mathrm{P}$ (2000). The impact of E. coli $\mathrm{O} 157: \mathrm{H} 7$ on the food industry. World J Microbiol Biotechnol 16:749-755

Mehdizadeh T, H Tajik, AM Langroodi, R Molaei, A Mahmoudian (2020). Chitosan starch film containing pomegranate peel extract and Thymus kotschyanus essential oil can prolong the shelf life of beef. Meat Sci 163:108073

Miller LC (1963). The British pharmacopoeia 1963. J Pharm Pharmacol 15:766-768

Moghimi R, L Ghaderi, H Rafati, A Aliahmadi, DJ McClements (2016). Superior antibacterial activity of nanoemulsion of Thymus daenensis essential oil against E. coli. Food Chem 194:410-415

Mossa AH, SL Afia, SM Mohafrash, BA Abou-Awad (2019). Rosemary essential oil nanoemulsion, formulation, characterization and acaricidal activity against the two-spotted spider mite Tetranychus urticae Koch (Acari: Tetranychidae). J Plant Prot Res 59:102-112

No HK, SP Meyers, W Prinyawtwatkul, Z Xu (2007). Applications of chitosan for improvement of quality and shelf life of foods: A review. J Food Sci 72:87-100

Noori S, F Zeynali, H Almasi (2018). Antimicrobial and antioxidant efficiency of nanoemulsion-based edible coating containing ginger (Zingiber officinale) essential oil and its effect on safety and quality attributes of chicken breast fillets. Food Contr 84:312-320

Ntzimani AG, VI Giatrakou, IN Savvaidis (2010). Combined natural antimicrobial treatments (EDTA, lysozyme, rosemary and oregano oil) on semi cooked coated chicken meat stored in vacuum packages at $4{ }^{\circ} \mathrm{C}$ : Microbiological and sensory evaluation. Innov Food Sci Emer Technol 11:187-196

Olaimat AN, RA Holley (2015). Control of Salmonella on fresh chicken breasts by $\kappa$-carrageenan/chitosan-based coatings containing allyl isothiocyanate or deodorized oriental mustard extract plus EDTA. Food Microbiol 1:83-88

Paparella A, A Serio, FD Pasquale, LD Nicola, C Chaves-López (2011). Antimicrobial activity of chitosan in pork loins. Ital J Food Sci 23:131-134
Petrou S, M Tsiraki, V Giatrakou, I Savvaidis (2012). Chitosan dipping or oregano oil treatments, singly or combined on modified atmosphere packaged chicken breast meat. Intl J Food Microbiol 156:264-271

Raeisi M, H Tajik, RS Razavi, M Maham, M Moradi, B Hajimohammadi (2012). Essential oil of tarragon (Artemisia dracunculus) antibacterial activity on Staphylococcus aureus and Escherichia coli in culture media and Iranian white cheese. Iran J Microbiol 4:30-34

Rao J, DJ McClements (2011). Formation of flavor oil microemulsions, nanoemulsions and emulsions: Influence of composition and preparation method. J Agric Food Chem 59:5026-5035

Restrepo AE, JD Rojas, OR Garcia, LT Sanchez, MI Pinzon, CC Villa (2018). Mechanical, Barrier, and Color Properties of Banana Starch Edible Films Incorporated with Nanoemulsions of Lemongrass (Cymbopogon citratus) and Rosemary (Rosmarinus officinalis) Essential Oils. Food Sci Technol 24:705-712

Ricci A, A Allende, D Bolton, M Chemaly, R Davies, PSF Escámez, R Girones, L Herman, K Koutsoumanis, B Nørrung, L Robertson, G $\mathrm{Ru}$, M Sanaa, M Simmons, P Skandamis, E Snary, N Speybroeck, BT Kuile, J Threlfall, H Wahlström, J Takkinen, M Wagner, D Arcella, MTDS Felicio, M Georgiadis, W Messens, R Lindqvist (2018). Listeria monocytogenes contamination of ready-to-eat foods and the risk for human health in the EU. EFSA $J$ 16:e05134 https://doi.org/10.2903/j.efsa.2018.5134

Shahbazi Y, N Shavisi, E Mohebi (2015). Effects of Ziziphora clinopodioides essential oil and nisin, both separately and in combination, to extend shelf life and control Escherichia coli $\mathrm{O} 157$ : $\mathrm{H} 7$ and S. taphylococcus aureus in raw beef patty during refrigerated storage. J Food Saf 36:227-236

Sharifi F, S Khanzadi, M Hashemi, M Azizzadeh (2017). Control of Listeria monocytogenes and Escherichia coli O157: $\mathrm{H} 7$ inoculated on fish fillets using alginate coating containing lactoperoxidase system and Zataria multiflora boiss essential oil. J Aquat Food Prod Technol 26:1014-1021

Souza VG, JR Pires, ÉT Vieira, IM Coelhoso, MP Duarte, AL Fernando (2019). Activity of chitosan-montmorillonite bionanocomposites incorporated with rosemary essential oil: From in vitro assays to application in fresh poultry meat. Food Hydrocoll 1:241-252

Souza VG, JR Pires, ÉT Vieira, IM Coelhoso, MP Duarte, AL Fernando (2018). Shelf-life assessment of fresh poultry meat packaged in novel bionanocomposite of chitosan/montmorillonite incorporated with ginger essential oil. Coatings 8:177

Yen MT, JH Yang, JL Mau (2008). Antioxidant properties of chitosan from crab shells. Carbohydr Polym 74:840-844

Youssef DY, DMA ELMasry (2018). Effect of chitosan-nanoparticles on the shelf life of chilled chicken meat and decontamination of Staphylococcus aureus and Salmonella typhimurium. Anim Health Res J 6:9-18 http://animalhealth.ahri.gov.eg/Home/Publication?id=1

Zhang J, Y Lv, B Wang, S Zhao, M Tan, G Lv (2015). Influence of microemulsion-mucin interaction on the fate of microemulsions diffusing through pig gastric mucin solutions. Mol Pharm 12:695-705 